\title{
The teachers' role in developing, opening, and nurturing an inclusive STEM-focused school
}

\author{
David Slavit ${ }^{*}$, Tamara Holmlund Nelson and Kristin Lesseig
}

\begin{abstract}
Background: This study is about teachers' collective activity during the development and initial year of a science, technology, engineering, and mathematics (STEM)-focused school in the USA. The target school of this study was inclusive, as it sought admission of students from varying backgrounds and levels of ability. Drawing from narrative inquiry and case study methodologies, we examine the collective work of the teachers in the target school from 6 months prior to school start-up through the end of the first year. We focus on visioning, collaboration, and curriculum development in our analysis of the teachers' collective work.

Results: We analyze the collective sense-making activity of the teaching staff regarding key facets of the start-up process. While the teachers received a variety of supports, including time and resources for collaborating, there was a lack of specific support for the conceptualization and creation of multi-disciplinary, STEM-focused projects. The risktaking and collaborative actions of the teachers led to three specific instructional approaches that were continuously adjusted to respond to the evolving vision of the STEM-focused school. The teachers also solicited the needs and interests of their students and utilized these in curricular design and instruction, which promoted student buy-in and participation. By the end of the school year, a common vision for STEM-focused, project-based learning was emerging, but not solidified.

Conclusions: Our study confirms the power of doing and risk-taking in teacher development, particularly in the ways in which teacher collaboration advanced curriculum and instruction in this STEM-focused school context. The intellectual supports that teachers require in this context are numerous and must be carefully identified and nurtured, and the subsequent teacher activity must be monitored as contextual shifts occur and sources of pressure (e.g., external learning standards) become relevant. The teachers' role is a complex mixture of learner, risk-taker, inquirer, curriculum designer, negotiator, collaborator, and teacher. Instructional and curricular supports require substantial time to synthesize and eventually enact, and more than a few months prior to school start-up are necessary to fully engage and prepare teachers for the collective task of visioning, collaborating, and planning the curriculum and instruction of an innovative school.
\end{abstract}

Keywords: Teacher development, School start-up, STEM schools, Innovative schools, Teacher collaboration, Teacher learning, Project-based learning

\footnotetext{
* Correspondence: dslavit@wsu.edu

Washington State University Vancouver, 14204 NE Salmon Creek Avenue,

Vancouver, WA 98686-9600, USA
} 


\section{Background}

Educational reform commonly ushers in new types of schools (Jennings 2012). A common example, currently found in numerous countries, is the creation of specialist or magnet schools that are developed to target specific academic areas, societal needs, or student populations (Gorard and Taylor 2001; Vopat 2011). The recent popularity of science, technology, engineering, and mathematics (STEM) as an integrated academic focus has recently led the way to a large number of STEM-focused magnet schools throughout the world, mostly in response to political and business calls for an improved workforce and a more STEM-educated citizenry. STEM-focused schools in the USA can be traced as far back as the early twentieth century (Erdogan and Stuessy 2015), and there has been a recent worldwide movement to develop STEM-focused schools. Currently, Australia, England, Scotland, and the USA have published national recommendations to support the growing STEM movement (Fan and Ritz 2014; Marginson et al. 2013; National Research Council 2011; Pitt 2009; Science and Engineering Education Advisory Group 2012), and many countries have developed specialized programs and schools that focus on STEM. For example, Australia, China, England, Korea, Taiwan, and the USA are developing K-12 STEM curricula that incorporate a multi-disciplinary focus with projectbased pedagogical principles (Fan and Ritz 2014). France, Japan, and South Africa have focused on informal, outside-of-school STEM experiences to address these challenges (Fan and Ritz 2014).

While extremely important to the STEM-focused school start-up process, adequately defining STEM is difficult, as Herschbach (2011) notes:

It is hard to discern what exactly is meant by "STEM." Practically any kind of educational intervention that is even remotely associated with science, technology, engineering or math is referred to as a STEM innovation. (p. 98)

We offer a definition provided by Nathan and Nilsen (2009) as a starting point for analyzing STEM as a curricular concept:

STEM education is an interdisciplinary approach to learning where rigorous academic concepts are coupled with real-world lessons as students apply science, technology, engineering, and mathematics in contexts that make connections between school, community, work, and the global enterprise enabling the development of STEM literacy and with it the ability to compete in the new economy. (p. 3)
But just as there are numerous working definitions of STEM, the structures and foci of STEM-focused schools also vary considerably (Erdogan and Stuessy 2015). For example, some STEM-focused schools target students with high-academic standing in STEM areas, whereas "inclusive" STEM-focused schools (National Research Council 2011) are designed to serve a broader population; no selective admissions criteria are used, and the goal is to attain student demographics that mirror those in the population at large. Inclusive STEM-focused schools seek to attract a more diverse student population and increase the opportunities for traditionally underserved students in STEM areas.

There are certain commonalities that exist to help define STEM-focused schools, including STEMfocused curriculum, technology use, and real-world STEM partnerships (Lynch et al. 2012). Many STEMfocused schools, particularly in the USA, also utilize project-based learning (PBL) as an instructional vehicle (Marshall 2010; National Research Council 2011; Lynch et al. 2012, 2013; Erdogan and Stuessy 2015). PBL has many forms but typically involves the use of extended, multi-disciplinary projects through which "all students engage in a common project with unclear processes but clearly identified expected outcomes" (Yetkiner et al. 2008, p. 1). PBL instruction targets the development of conceptual knowledge and application through extended learning experiences around a focus or theme, while also promoting critical thinking, communication, and collaboration (Larmer and Mergendoller 2010). PBL instruction meshes with the STEM movement, as it is a natural platform to promote multi-disciplinary curriculum and inquiry-based educational experiences that are common in STEMfocused schools (Pfeiffer et al. 2013). However, multidisciplinary, project-based curricular efforts have received significant criticism in the past, particularly related to inadequate disciplinary rigor or inauthentic integration across disciplines (Wineburg and Grossman 2000; National Research Council 2011; Erdogan and Stuessy 2015). These are important concerns for those designing STEM-focused schools.

Despite the lack of a clear and consistent vision of STEM and a dearth of research-based instructional materials, STEM-focused schools are opening at an accelerating rate. Because implementing a STEM-focused, project-based curriculum often requires new instructional and assessment practices, support for the planning and development process can be crucial. This is especially true regarding the intellectual supports required to assist teachers in creating and enacting an instructional and curricular vision. Adequately coordinating key disciplinary content and practices in a STEM-based PBL environment often requires new instructional norms and 
practices. However, there is little research on the ways that teachers collectively recreate or reimagine curriculum and instruction as they actively plan and start-up these schools. Descriptive studies are needed to show what teachers do, the questions that arise, and the adaptations (and accompanying resources) that are enacted in order to inform future start-up and development of schools in the current STEM era.

\section{Influences on school start-up}

Much of the literature related to school start-up has focused on charter schools (also called down-sized or foundation schools), which have a specific mission and a degree of operational autonomy. Research shows that the development of these schools is dependent on a variety of educational, environmental, social, and economic factors. For example, Darling-Hammond et al. (2002) conclude that a charter school's successful start-up is related to (a) small school size; (b) structures that allow for personalization and strong relationships; (c) a carefully constructed curriculum aimed at specific proficiencies; (d) teachers' pedagogical approaches, especially their explicit teaching of academic skills and their ability to adapt instruction to students' needs; (e) a school-wide performance assessment system; (f) the creation of flexible supports to ensure student learning; and (g) strong teachers supported by collaboration in planning and problem solving.

Because innovations often challenge existing educational structures and norms, there are expected challenges to any innovative school start-up effort. These can include a lack of access to material and personnel resources, funding, time and space for planning, and knowledge of the school start-up process (Winger 2000). Turbin (2009) claims that planning an innovative school is an "oxymoron," as the act of planning seeks to clarify and reduce risk, while innovation stresses risk-taking and experimentation. Turbin (2009) found that innovative schools can "regress to the mean," although shared vision, shared decision-making, ongoing reflection on and evaluation of the planning process, and connections between people and activities can help mitigate this challenge. However, in the midst of innovation, changes in the school context, such as decreased funding or increased accountability measures, may lead to significant ripple effects that impact the organizational plan and disrupt the school's development. Giles and Hargreaves (2006) offer a pessimistic view of innovative school startup, stating that "an 'attrition of change' leads to the school's seemingly inevitable decline" (p. 125). Hargreaves (2003) has stated, "It is not innovative schools we need, but an innovative system" (p. 38).

Research on STEM-focused schools is rather limited, especially in regard to school start-up (Honey et al. 2014).
A case study of an inclusive STEM-focused school in the USA found that specific attention to the development of school culture involving both teachers and students was essential to achieving the school's vision (Rhodes et al. 2011). Along with dedicated faculty collaboration time, initiatives such as uniforms and making STEM socially prestigious supported the creation of a positive, STEMfocused school culture. Tan and Leong (2014) investigated a school in Singapore in which the teachers developed their own STEM-based curriculum over the school's first 3 years. While they found this process provided important learning opportunities for the teachers in regard to curriculum and instruction, it also presented significant challenges in regard to providing adequate formative and summative student assessments. Morrison et al. (2015) found that creating a culture of student inquiry around STEM-based problems supported a teaching staff in continuously generating curriculum and enacting the school vision. It would seem that teacher collaboration, an engaging and inquiry-based curriculum, and specific efforts to develop a STEM-focused learning culture are important parts of STEM-focused school start-up. At a policy level, Johnson (2012) found that long-term planning, leadership, resources, and commitment were essential to the development and start-up of STEM-focused schools and initiatives.

Lynch et al. (2013) pose several research challenges for STEM-focused schools, the first of which is, "What are they and how do they work?" Research on the conceptualization, development, and enactment of STEM-focused schools can provide useful information to help address this important research challenge.

\section{Conceptual framework}

Our analysis of STEM-focused school start-up emphasizes the collective teacher activity inherent in this process. Lynch et al. (2012) provide a conceptual framework for researching STEM-focused schools that incorporates (1) the interaction of the school's design dimensions (including goals and curriculum), (2) implementation practices, and (3) student outcomes embedded in the systemic factors and unanticipated side effects that moderate the school context. Because we are especially interested in teacher collective activity in the context of the start-up of STEM-focused schools, we have chosen to emphasize the first two of these research design principles. We have chosen to focus on student outcomes only from the perspective of how they impact teacher activity.

Our framework draws on social constructivist theory (Vygotsky 1978; Cobb 1994) that emphasizes sensemaking activity in the context of social mediation and negotiation. We specifically draw on Lave and Wenger (1991) notion of community of practice, which embeds 
both knowledge and the process of constructing knowledge inside cultural practices. By examining communities of people who share practice, such as teachers attempting to start a STEM-focused school, the acts of participation in this practice reveal the collective sensemaking that emerges from these activities. When teachers work together, they have opportunities to "share understandings concerning what they are doing and what that means in their lives and for their communities" (Lave and Wenger, 1991, p. 98). Therefore, our analysis focuses on both the processes and products of the teachers' collective sense-making activity in the context of school start-up (Wilson and Berne 1999).

Our framework is informed by perspectives that seek to understand collective activity from a sense-making perspective. Drawing on both Vygotsky and Piaget, Cole and Wertsch (1996) cite the "primacy of cultural mediation" in considering sense-making activity, although the forms of cultural mediation (including the need for language) can vary from context to context. Sense-making, from this perspective, is a negotiated experience dependent on thought, activity, and tools. Further, sense-making can occur in rather natural, unfiltered ways and is the core process of developing understandings. Weick et al. (2005) state:

Sensemaking is, importantly, an issue of language, talk, and communication. Situations, organizations, and environments are talked into existence. (p. 409)

Put briefly, sense-making is the process of conceptualizing the world (Rosebery and Puttick 1998) that can be made visible through an examination of the activity and tools embedded in a situation. Using this framework, we focus our work on teacher collective activity and the ways in which a shared experience (opening a new, innovative school) leads to a negotiated sense-making process and how this subsequently leads participants to specific roles in this shared experience.

\section{Research questions}

What is the teachers' role in developing a vision and shared understandings of STEM-focused, project-based curriculum and instruction in a new inclusive, STEMfocused school?

A. How do teachers make sense of STEM-focused, project-based curriculum and instruction while developing a vision for an innovative, STEMfocused school?

B. How are these understandings and vision enacted and operationalized during school start-up? What supports and constrains these efforts?

C. How do teachers respond to student needs within these efforts?

\section{Methods \\ Methodology}

We report on a 15-month case study, which includes 6 months prior to the school opening as well as the first academic year. Case study methods were chosen to allow for a focus on specific phenomena in a specific context. We follow Stake's (1995) conception of case as a bounded, dynamic system with both empirical and interpretive aspects. Our design was flexible in that we consistently challenged our hypotheses and altered our data collection when new phenomena were revealed or in the event of confirming and disconfirming evidence. Observation and interview were our primary data sources. The research team consisted of the first two authors and three research assistants. The research team met approximately twice per month to discuss findings, formatively assess the project direction, and develop or retool data collection instruments.

The methodology followed a narrative inquiry approach to understanding and describing situated activity (Clandinin and Connelly 2000; Creswell 2008). Narrative researchers "describe in detail the setting or context in which the participant experiences the central phenomenon" (Creswell 2008, p. 522). In the case of this study, the teachers are the primary participants, and the imagining, planning, and developing of a new STEM-focused school is the central phenomenon. Narrative researchers do not merely tell stories, but interrogate a narrative through inquiry that makes use of both personal experience and in-depth analyses of data. Narrative researchers often share many experiences with participants and include participants as active members of the analytic process (Clandinin 2013). In this study, the researchers were co-participants in the central phenomenon but played only minor roles relative to the participants. Further, while our own biases and experiences clearly shaped the data collection and analysis, we strove to minimize our participatory roles as much as possible. Our participatory approach to the narrative inquiry would be described as moderate by Spradley (1980), as we sought insider status and participatory engagement, but also sought minor roles of participation in order to minimize our presence in the phenomena under investigation. The specific roles of the researcher and relationship to participants are more fully described below.

\section{School context}

Ridgeview STEM Academy (RSA, pseudonyms used throughout) is an inclusive, STEM-focused school in the northwest USA serving students in grades 6-12 (approximately ages 12-18). RSA is in a large, suburban school district that used a lottery to obtain students with achievement test scores and demographics (e.g., $35 \%$ non-White ethnicity, $53 \%$ receiving subsidized meal 
support) that closely mirror those in the geographical area in which it is located. In year 1, the target year of the study, only students in grades 6,7 , and 9 attended RSA, with approximately 60 students at each level. Grades 8 and 10 were added in year 2, with a full complement of grades 6-12 reached in year 4. While philosophically and structurally a single school, students in the middle school (grades 6-8) and high school (grades 9-12) were housed in separate buildings approximately $5 \mathrm{mi}$ apart. RSA utilized one-to-one instructional technology, as each student was provided a laptop that was fully integrated into the learning process, including use as information conduit, assignment submission portal, and most importantly as a primary learning tool. Ten teachers, a counselor, and a lead administrator (principal) comprised the school staff in year 1 (Table 1). The teachers were a mix of recognized leaders in the district and teachers new to the district. Only one teacher (Paul) had extensive prior PBL experience. The principal had a strong science background with prior administrative experience in the district.

\section{Data collection}

Data were collected from a variety of sources using both qualitative and quantitative methods. All 12 members of the school staff were active participants in the study, and $86 \%$ (135 of 157) of the students participated. Selected sixth, seventh, and ninth grade students also participated in focus group interviews at the end of year 1, with selection based on availability and gender representation.

The first two authors were participants on various district- and building-level committees that supported school start-up. Both were members of the school's advisory board and collectively attended each meeting during the school year. Participant observation notes and artifacts were collected in each of these roles.

\section{Teacher data}

The first two authors attended weekly teacher collaboration meetings at least once per month, mostly in an observer role but participating when requested. Observations focused on collaborative processes, visioning, and curricular and instructional development. The first two authors also each engaged in numerous informal conversations with the participants throughout the study.

Observations were also conducted in mathematics and science classrooms on a weekly basis. The researchers used an observation protocol that focused on mathematics and/or science content, lesson structure and instructional delivery, connections to STEM contexts and careers, and student mathematical and/or scientific activity (e.g., problem solving, reasoning, justification). The researcher played no role in the instruction. Informal conversations with students and the collection of student work and other artifacts (e.g. lesson plans, pictures of instructional materials) occurred during each of these observations. Syllabi and additional instructional materials were also collected from the school's online learning management system.

Formal interviews with the principal and teaching staff were conducted near the end of the school year. These interviews focused on school vision, the nature of the school's teaching and learning processes, and the nature of support received. All but one of the interviews were audio-recorded and transcribed.

\section{Student data}

Nearly all of the students (86 \%) were surveyed at the beginning and end of the school year. Half of these students took a survey focused on mathematics instruction and half on science instruction. The pre-survey asked students to comment on their experiences in the prior

Table 1 Instructional and administrative staff at RSA

\begin{tabular}{lllll}
\hline & Teaching area & Teaching experience (pre-RSA) & Masters degree & Additional certification \\
\hline Alicia & Physical education & $21+$ & $Y$ & Administrative certification \\
Brent & Special education & $11-15$ & $Y$ & \\
Clare & Language arts & $6-10$ & $Y$ & \\
Greg & Mathematics & $11-15$ & $Y$ & \\
Josh & Art/technology & $0-2$ & $Y$ & \\
Kim & Global forum & $3-5$ & $Y$ & National board; ESL \\
Laura & Spanish & $6-10$ & $Y$ & Administrative credential (near completion) \\
Michelle & Language arts/social studies & $6-10$ & $Y$ & \\
Paul & Science & $21+$ & $Y$ & Administrative credential (near completion) \\
Will & Social studies & $11-15$ & $Y$ & Counseling \\
Erin & Counselor & $0-2$ & $Y$ & Former HS science teacher \\
Sandra & Principal/lead school administrator & $6-10$ & $Y$ & \\
\hline
\end{tabular}


school year, and the post-survey asked for reflections on year 1 at RSA. Short response items on the surveys asked students to comment on the nature of classroom activity and identify specific supports for their learning. Three closed-response items asked what the students and teachers most commonly did during instruction (e.g., "listened to the teacher talk" or "talked and listened to my classmates").

Student focus group interviews were also conducted at the end of the school year. Two groups consisting of three and four students participated at the middle school (grades 6 and 7) and one group of six students participated at the high school (grade 9). The interviews contained a series of questions focused on school identity, the students' place or role in the school, and the nature of their learning experiences. However, in many instances the conversation strayed from these topics, which we allowed and actively pursued.

\section{Data analysis}

A sociocultural lens (Wells 1999) was employed in the context of the overall analytic framework. Given our emphasis on teachers as a community of learners (Lave and Wenger 1991; Borko 2004), we focused our analysis on collective sense-making and teacher activity that "seeks to understand by collaborating with others" (Wells 1999, p. 121). Hence, the unit of analysis was the teacher group, and the object of analysis was the collective sense-making activity that defined the ways in which the teachers imagined, developed, and enacted curriculum and instruction in the context of school start-up.

Case study methodology using categorical aggregation was employed (Stake 1995). In this approach, data analysis is "a matter of giving meaning to first impressions as well as to final compilations" (Stake 1995, p. 71). Hence, data were analyzed in an ongoing manner to allow for a continually progressive development of theories and findings. A constant comparative method of analysis was employed for the specific development of theories and eventual results (Glaser and Strauss 1967; Taylor and Bogdan 1984).

Throughout the data collection, the research team met twice per month to discuss the latest data collected, plan future data collection, and provide updates on potential findings. Individual researchers analyzed data between meetings to prepare for these discussions. As initial themes emerged, more specific codes emerged. The first two authors revisited various data sets to confirm or disconfirm working theories and refine codes, which were subsequently discussed by the entire research team. Analytic memos were also maintained and discussed, and more refined themes emerged. Analytic diagrams were created, and subsequent themes were shared with
RSA teachers and school administrators to provide member checking, additional clarity, and improved validity (Taylor and Bogdan 1984; Miles et al. 2014). The final set of themes that emerged as most salient to the case were located in the following areas:

- Teacher collaboration

- School vision

- Curriculum and project-based learning (PBL)

- Responding to student needs

These themes shaped the final revision of the research questions (see above) and framed our analysis of teachers' collaborative activity and sense-making related to curriculum and instruction at RSA.

\section{Results and discussion}

We explore the teachers' roles in the school start-up process by first discussing the ways in which they attempted to develop and nurture a vision for the school. We specifically focus on their collective sensemaking related to curriculum, instruction, and students. Second, we discuss the ways in which these sensemaking processes were enacted by the teachers during the initial school year. We discuss the key events and outcomes related to the collaborative instructional processes in which the teachers engaged, including the development of a collective vision and materials regarding STEM-based, multi-disciplinary curricula and a PBL approach to instruction. Finally, we discuss the ways in which the teachers responded to the needs of the students throughout this process.

Teachers' role in developing, nurturing, and adapting an overall school vision

Developing a vision: teacher activity and sense-making

The teachers at RSA were supplied an initial school vision by district administrators and attempted to adapt it to fit their own instructional approach and the needs of their students. RSA was planned to be an inclusive school-a school with equal access for all students. The only requirement to attend RSA was to apply and be present at one of the school's information nights. The district had a definite vision for the school, led by the superintendent (the chief district administrator) who was the main initiator and lead champion of the school's development. However, the vision was also assumed to be malleable as the school matured. One of the first school vision statements identified "empowerment, inquiry, and STEM" as the "core values" of the school. It emphasized the student as a learner, collaborator, designer, and connector, with specific direction to move project-based learning (grades $6-8$, developing products) to problem-based learning (grades 9-10, focus on solving 
problems and acquiring knowledge) to practice-based learning (grades 11-12, focus on real-world STEM experiences through internships and early college learning opportunities).

Over the course of the study, the teachers spent considerable time and effort making sense of this school vision and molding it to fit their own goals and needs, as well as to the needs of the students at the school. During the summer prior to the school's opening, the teachers engaged in approximately 20 days of PD stretched across 3 months to help advance this vision and translate it into practice. This district-led PD focused on building community among the teachers and developing instructional knowledge in support of project-based STEM curriculum and instruction. Overall, the teachers felt that the length of the PD did not provide sufficient time for all that was necessary in the school start-up phase, including comprehending and reacting to the school vision laid out by the district. Most teachers also expressed initial anxiety about their instructional preparedness in this innovative school setting. This was due to their overall lack of experience with PBL and STEM-focused instruction and was heightened by the fact that the school was to open in just 3 months.

Early in the summer, the teachers initiated a lengthy conversation about the district's expectations of them, as well as the overall instructional approach at the school. The main message projected was that everyone would learn from the process, and that patience and flexibility would be needed in constructing a vision and instructional approach. A high-ranking district administrator stated, "I give you explicit permission to try new things," relieving anxieties among the teachers who came from schools within the district that had more traditional instructional norms. The freedom to be innovative and take risks would prove pivotal in the trajectory of the teachers' collective sense-making activity and therefore in shaping the subsequent curriculum and instruction that emerged at RSA.

Teacher collaboration to create and implement a multi-disciplinary, project-based curriculum was a prominent part of the district's vision of the school, which was reflected in the initial sessions of the summer PD. Once the initial vision and work norms were negotiated, the teachers began to concentrate on developing instructional approaches and materials for the coming year. The teachers were initially asked to individually brainstorm important themes that might relate to the major content areas and student learning goals of their courses and then collaboratively develop a matrix to find intersections across their individual content-based themes. A specific process to do this was not provided, and the teachers' limited knowledge of PBL led to initial confusions about this work. Three approaches surfaced among the teachers in making multi-disciplinary connections: (1) connecting themes and content across courses, (2) identifying multi-disciplinary "big ideas" that could support integration, and (3) developing projects and working backwards to fit in disciplinary content. As a result, while the teachers began to learn how to collaborate with each other and generated some very good ideas for multi-disciplinary projects, few classroom-ready projects were created during this time.

Despite the abovementioned activities and support structures, many teachers felt that both the teaching staff and students began the year with an ambiguous understanding of the school's vision, as well as the nature of the curriculum and instruction to be realized. As Clare stated, "Neither teachers nor students knew what they were getting into." Most teachers felt that the vision of the school created by the district was unclear, and some felt that the curriculum and instruction being envisioned was too theoretical in the context of the instructional realities faced by the teachers. Most teachers felt they lacked structured, detailed knowledge of PBL instructional approaches and the ability to adequately develop meaningful projects during this initial phase. The teachers learned to collaborate but entered the school year with an unformed collective vision of the school and limited instructional resources in which to enact it. As will be seen, the teachers were able to eventually build on these experiences and generate individual and collective understandings of curriculum and instruction during the school year, which they collaboratively translated into three specific approaches to enact the school's vision of STEM-focused PBL instruction.

\section{Incorporating student needs into the vision}

Although the district supported the teachers in developing an understanding of the incoming students prior to the school's opening, the teachers also felt they needed a better understanding of the students who were to attend RSA in order to tailor projects to their interests, needs, and capabilities. The teachers were presented data that contained information on the students' demographics (Table 2) and a short written response from each student on why they wanted to attend the school. From these data, the teachers concluded that the students were interested in solving realworld problems and engaging in hands-on learning and were dissatisfied with prior school experiences. Other more specific conclusions were made, including "lots of males mean lots of kinesthetic learners" and a recognition that some students lacked adequate preparation in mathematics and science. Many teachers felt that their students were being "brave" to try a new school, particularly girls who are less likely to attend STEM- 
Table 2 Demographic data gleaned by teachers from student surveys

$73 \%$ male, $27 \%$ female
$42 \%$ below benchmark in writing
$29 \%$ below benchmark in math
$37 \%$ below benchmark in science
6 students had below $80 \%$ in attendance
110 students were ready for honors or benchmark classes
8 students required remedial courses
Lower percentage of Hispanic students than district average-10\%
vs $18 \%$
24 students speak a language other than English at home, primarily
Spanish
3 students coming from non-public schools
3 english language learners
16 students on a special instructional or behavioral support plan
16 students previously in an academically advanced program

focused schools. The teachers made several instructional implications from the understandings gained from these data, including the need for hands-on instructional approaches and considerations of gender when organizing group work. The teachers identified "lots of high-achievement kids" but also noted that "we can't forget the others" and developed pre-assessments to identify the specific needs of "the lower-level kids." Upon the conclusion of this analysis session, the teachers stated that they "were in this together" and were "ready to teach to all kids."

The student data also revealed that some students were coming to RSA for tangential reasons (e.g., feeling they would not fit in at a "typical" middle or high school, wanting to be at a small alternative school, submitting to a parent's desire to attend), rather than for a specific interest in STEM. The teachers were quite surprised by these data, given their STEM-based perceptions of the school. The teachers also expressed wariness of potential divides that might arise between students who held different degrees of passion towards STEM, but they also saw this as a potential opportunity to create a diverse community of learners.

\section{Contextual constraints on the developing school vision}

Three important contextual constraints impacted the teachers' role in the school start-up by disrupting their collective ability to adequately respond to the school vision. These constraints were the curricular and instructional demands imposed by external learning standards, the physical split of the school, and a diversity in the students not anticipated by the teachers.
Sandra, the school's lead administrator, saw the focus on STEM at RSA this way:

We use the term we have to STEMify everything. So what we're trying to have is-because we are obligated to cover all the content areas that our state requires-finding the natural connections. So it's not everything will be driven by math and science, but where we can, we can fit in.

The teachers at RSA were responsive to the standardsbased demands of current educational reform. As stated by Sandra, this required addressing a large set of specific student learning goals in a variety of content areas demanded by external mandates. This complicated the teachers' efforts to construct multi-disciplinary projects during the summer PD, limiting their response to the school's vision. The teachers were struggling to balance the district's vision for the school, the needs of the learners, the realities of their instructional situation, and the demands to cover mandated content-specific learning goals.

The evidence suggests that, at the beginning of the school year, connections across disciplines were not being made in satisfactory ways. The teachers felt the STEM-based projects they developed in the summer failed to support multi-disciplinary content consistent with the content-based expectations they held for their own courses. As we will see, this led to further teacher collective activity and innovation and multiple approaches to enact the school vision.

Second, the lack of a unified physical space also impacted the vision and collective work of the teachers. The district envisioned RSA as a unified school, but due to space and budget constraints, students in the middle and high schools were located in separate buildings approximately $5 \mathrm{mi}$ apart. This physical split led to complications related to teacher collaboration as well as a lack of unified identity across the middle and high schools. Clare reflected on this situation near the end of year 1 , noting that the physical split among the students was also impacting the development of an overall school vision:

I think we're all still kind of figuring that (the vision) out. I think it will really depend on what it eventually looks like when we get new batches of kids in. Until the current middle school kids get to high school it's going to be two different schools.

The geographic split of the school led to the formation of two teacher cohorts, known as the A and B teams, who taught on alternative days at the middle and high school. While all teachers met weekly in a collective manner during collaborative planning sessions, a partial 
split among the teachers emerged as a result of this situation. Stephanie explained it this way:

We hardly connect because there's just not that time to connect. We only connect for an hour every Friday. So my teammates here, we collaborate quite often.

And there are a lot of ideas. But the other team, we don't see them a great deal.

The separation of the middle and high school was not part of the initial district vision of RSA but arose due to budget constraints. This separation proved to be a challenge to the vision building and collective sense-making of the teachers, as the creation of two instructional teams broke down collaborative opportunities.

Third, unexpected diversity among the student population also posed challenges for the teachers in developing and enacting the school vision. For example, Josh expressed surprise at the lack of students with high affinity toward STEM areas, stating, "I didn't anticipate there being the level of students that were not totally sold out for STEM." Clare expressed similar feelings regarding academic preparation and desire, stating, "I got the impression that all of our students were going to be high-achieving students, and I got the impression that they all were going to this school of choice, that they wanted to be here."

The RSA teachers utilized their emerging understandings of the learners at RSA to make several adjustments throughout year 1 in order to meet the learning and attitudinal realities of their diverse students. All of the teachers had initially envisioned the school's identity around STEM, with students playing a key role in that identity formation. However, their initial vision was based on incomplete information about the actual student demographics. In addition, the district did not adequately relay the inclusive vision of the school to the teachers prior to the summer PD. These two factors led to significant rethinking of the school's identity by the teachers as they better understood their students, which was aided by the analysis of student data described above. The district's initial vision of the school was modified by the teachers as they began to plan the school start-up, and subsequent revisions of the vision were made by the teachers as they learned more about their specific instructional context and the needs of their learners.

These external constraints pressed against the vision and instructional realities being developed by the teachers. Through their collective sense-making activity, the teachers' understandings of the incoming students and their curricular and instructional vision grew, but the shifting contexts which defined their instructional reality led the teachers to constantly review and modify their approaches.
Teachers' enactment of their collective sense-making and vision related to curriculum and instruction STEM-focused curriculum

Teacher collaboration and project-based instruction were significant factors in the development of RSA as a STEM-focused school, and the vision of Sandra provided a key support in this process as the school year unfolded. Two prominent components of Sandra's vision helped shape the teachers' collective activity related to curriculum throughout the year. First, Sandra and the teachers felt that student learning should occur simultaneous to engaging in the activities of the projects, and second, they sought to integrate content knowledge and produce multi-disciplinary learning experiences. Following the vision of Sandra, the teachers wanted the projects to be the "main course," not "dessert"; learning should be accomplished through completion of the project, rather than the project as an application of learning that has already occurred (Yetkiner et al. 2008). Sandra also felt the teachers needed to cover all required content standards "but with a STEM twist," and connections should be made across content areas as much as possible. However, the demands on each teacher to cover specific content goals threatened their efforts to integrate STEM concepts and practices through multi-disciplinary projects. The teachers struggled to maintain high cognitive demand regarding their own content learning goals inside the multi-disciplinary projects and grew dissatisfied with this approach. While "new and interesting," teaching content through STEM-focused projects challenged the teachers' collective ability to simultaneously maintain high-level student learning goals.

During the year, the teachers continued to be given opportunities to advance their understandings of multidisciplinary STEM-based curriculum. Each week, all RSA teachers met collectively for $1 \mathrm{~h}$ with the stated goal of collaborating on multi-disciplinary projects. The teachers facilitated these meetings, as Sandra was obligated to attend a district meeting at that time. Field notes from these sessions show an emphasis on teacher work related to content integration and instructional implementation of the group projects. This was the clear focus of this main teacher collaboration time, with the goal of developing STEM-related "real world" collaborative projects. Despite the visioning supplied by the district as well as Sandra, the teachers mainly credited each other for developing curricular ideas and materials, as Will stated:

It amazes me sometimes, when I sit in our collaboration meetings at the ideas that people come up with. And how they can gear their subject towards how other subjects are doing something. Like the migration project. You know how the science teacher was able to tie in the 
migration of things with the humanities part, and the social studies. And even Spanish. The ideas that come to the table. And so I think as the year has progressed and we got to know each other better, the planning has gotten better also.

While some teachers felt the school was doing an adequate job of building STEM-based, multi-disciplinary curriculum in a collaborative manner, particularly given the fact that they were "starting from scratch," others felt a need for continued improvement and revision. In general, the teachers appreciated the opportunity to work with colleagues and found the interactions beneficial but desired more awareness of how to fully integrate STEM into projects, particularly in regard to placing mathematics and science more at the source and core of projects. Moving beyond "STEMification," which the teachers began to view as a relatively inauthentic integration of STEM and non-STEM disciplines, was an ongoing challenge, but by the end of the year, the teachers felt progress was being made:

I'd say that there's a very clear focus on the goals of this school and on moving students, you know, getting them excited about project-based learning and about STEM, and getting at their thinking. Because those are what stand out to me as being our main goals, is getting at the way kids think. And preparing them for careers in STEM fields. And I'd say our teachers are doing a really great job doing that. I know at this point of the year, I think kids are really excited about project-based learning, once they've had a chance to get used to it and learn what it means. And the stuff that they're creating is amazing.

The collective vision of providing authentic STEM experiences through project-based learning included connecting the curriculum to societal applications, quite often driven by the teachers' growing awareness of student interests. One manifestation of this approach is told by a high school student:

We all are going to this school for a reason. It may not specifically be engineering or technology, but for example some of my friends are interested in programming. So one day they talked to our teacher about it and she said, "Okay, well I think I can help you out." And she brought in a college student who is focusing on technology and design and websites and that sort of thing to talk to the class for a bit. And so I think that the teachers just sort of pick up on what kind of path our careers are headed in and then they try and help us as best they can towards that goal.
Another student stated, "You get to talk to a lot of professionals of the field that you're interested in. They bring in all sorts of engineers and designers and everything here." RSA teachers also instituted field trips to a local creek and dam in support of multi-disciplinary projects. These explicit connections to STEM-based contexts and careers were consistent with the teachers' collective vision and helped define their approach to STEM-based curriculum and instruction.

\section{PBL instruction}

While the teachers at RSA received a broad, initial vision of PBL from both Sandra and the district, the teachers did not receive any additional theoretical or implementation frameworks for enacting PBL. This led the teachers to utilize the emergent discussions that occurred during the summer PD as the basis for their individual and collective approach, which they subsequently built upon throughout the year. The teachers developed their own PBL instructional framework in the summer prior to start-up (Fig. 1), which placed themes as the overarching intellectual driver of multi-disciplinary curriculum. Clare articulated an important realization she made early in the school year regarding the role of STEM and the enactment of PBL at RSA:

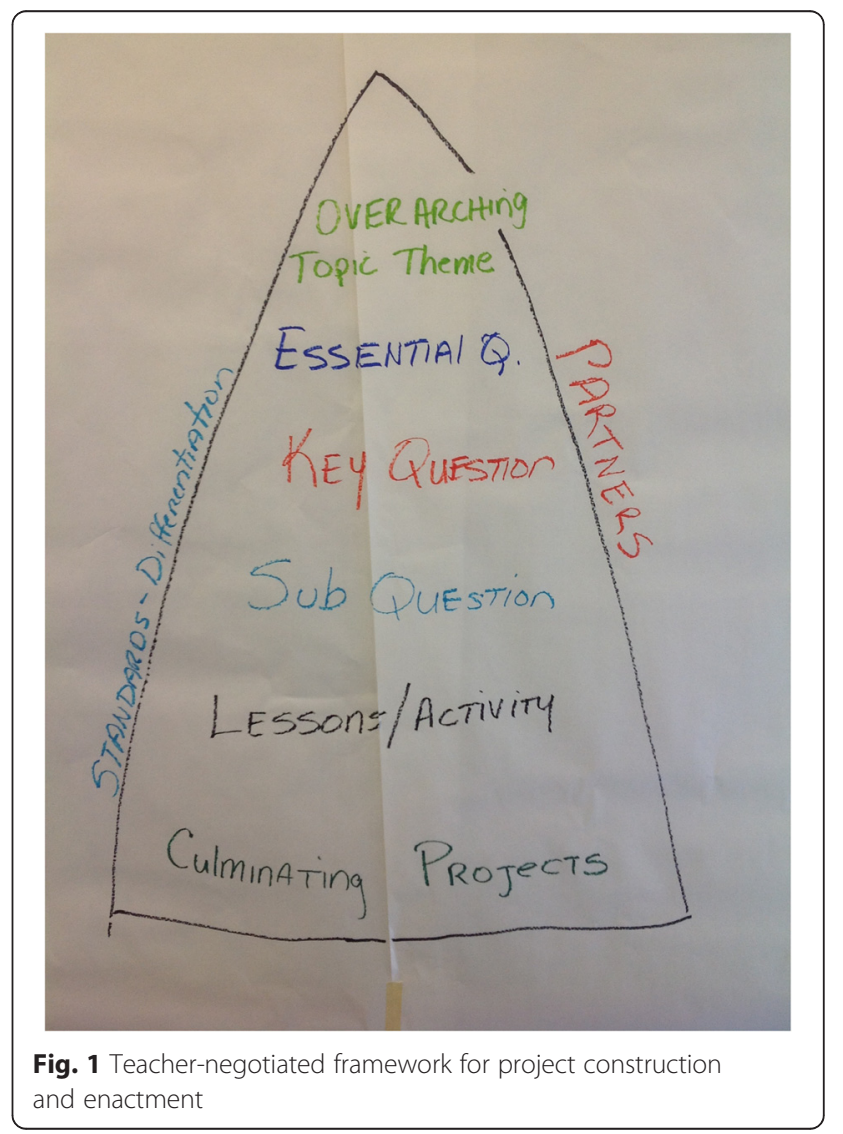


We were trying to focus on project-based learning, and nobody had any idea what that looked like. And I had this crazy moment of clarity in which one of my colleagues...we referred to it as the "project-based learning smack down," because I think at some point each of us had this realization that we had been designing curriculum that didn't fall within projectbased learning. Mine happened about ten days in. It was on the tenth day when one of my colleagues was like, "So I feel like you're doing projects as dessert and not as the main course." And I said, "Yeah. What?" And she was like, "So they have to learn through projects." And I was like, "What? I don't...what?"

The recognition that content could be taught through project implementation was an important shift in the RSA teachers' collective approach. However, the teachers noticed specific, nuanced distinctions across their own approaches to PBL, including a contrast between (1) the use of a single theme in which content could be embedded and (2) the intentional connecting of content from various academic areas. These perspectives represent two different interpretations of the school's vision, the first leading to the label of "STEMification" of the curriculum by embedding STEM concepts into an overarching theme, and the other seeking more authentic connections between specific non-STEM and STEM-based content through the identification of overarching concepts and processes. Some teachers saw the former approach as dominant at RSA and desired a change. Specifically, they wished to move away from developing separate projects that fit under a single umbrella topic towards integrated learning experiences that build upon one another. For example, the latter might involve work that was researched and fact-checked in science class, analyzed in mathematics class, addressed a historical question, and then was written up in language arts. Conducting a lab about erosion in science and then reading a book about farming in English with no deliberate attempt to connect the learning experiences might be thematic, but not truly integrative. Teachers began to note differences between projects that "seemed like good ideas" and projects that were truly STEMfocused and integrated thoughtfully. As Greg stated:

What happened was kind of we had this general theme, and each person applied their own, "Oh, this would work good for me in this portion of my class." So it was a bunch of independently-produced products pulled together at the end for the showcase, as opposed to, "What you're doing builds on what I'm doing builds on what the third person is doing." So, more like independent widgets that came together at the end, as opposed to those things working together all along.
The specific evolution of the collective approach of the teachers took three distinct forms, beginning with disjointed efforts to enact projects and culminating in a theme-based approach. First, the teachers took an approach to PBL that involved numerous single-disciplinary projects early in the year (Fig. 2). For example, during the first few weeks of the school year, the students were presented with large-scale projects related to farming in each of their classes. The teachers felt this satisfied the current instructional vision at RSA, as it presented a topic through several disciplinary lenses but also allowed for coverage of their own specific content goals. However, this overwhelmed the students, who had several projects due at one time, and initiated a collective reflection by the teachers on project coordination. The teachers were excited by their collaborative instructional approach, but felt the connections across content areas were being minimized, and recognized the students' needs for a reduced work load:

What I think all of us did at the start of the year was kids were taking eight classes and they had eight different projects. And they were almost in sync, in a cycle. So they would have low stress, low stress, just kind of hanging out, working on a project. And then, Bam! "This week eight projects are due!"

Second, the teachers made use of their collaboration time to discuss needed changes in their approach, and approximately one fourth of the way through the school year decided to decrease the number of projects and focus on integrating content across specific courses rather than every course (Fig. 3). However, time demands and perceived discrepancies in learning goals across content areas were among the factors that limited this approach. Paul stated:

So we had these big framework ideas and agreements, which was the positive, but you know when you get down to actually designing individual lessons, and "How does your science lesson blend with your English lesson? With your social studies lesson?" Yeah, then we didn't really get to do that.

The teachers again utilized their growing understandings of STEM-focused, project-based curriculum and instruction to adjust their collective approach. Over halfway through the school year, a third way of enacting cross-disciplinary projects was explored (Fig. 4). The teachers negotiated a theme that was used as a vehicle for the development of instruction that overlapped each of their courses and used essential questions as the primary connection of instructional activity across courses. Observations and interviews show that this did not necessarily lead to deep multi-disciplinary content 


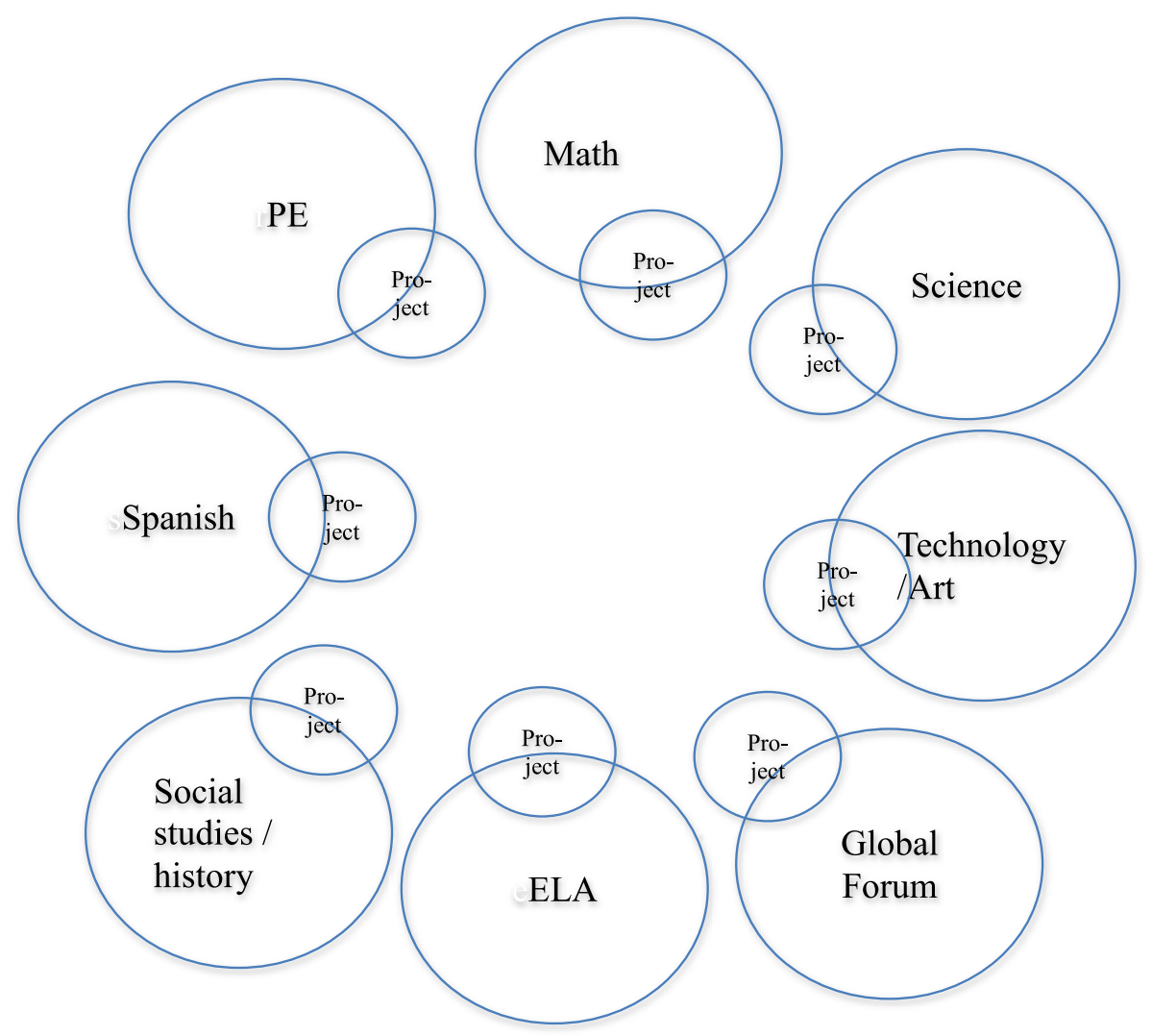

Fig. 2 Many projects, single disciplines

connections in the overall instruction, but the teachers increased their ability to talk about related ideas across their classes. For example, the theme of "Imagine Tomorrow" focused on the general notion of sustainability and concluded with a summit that involved student presentations to external audiences that incorporated various content areas on a variety of issues related to sustainability. During the final months of the school year, the teachers created other multi-disciplinary projects related to resiliency and immigration. These were implemented in a cross-disciplinary, collaborative manner in all classes simultaneously. The teachers had the freedom to innovate and take risks, and they made use of their opportunity to experiment, analyze, and adjust their collective approach to curriculum and instruction. These changes in instructional approach were due to both the

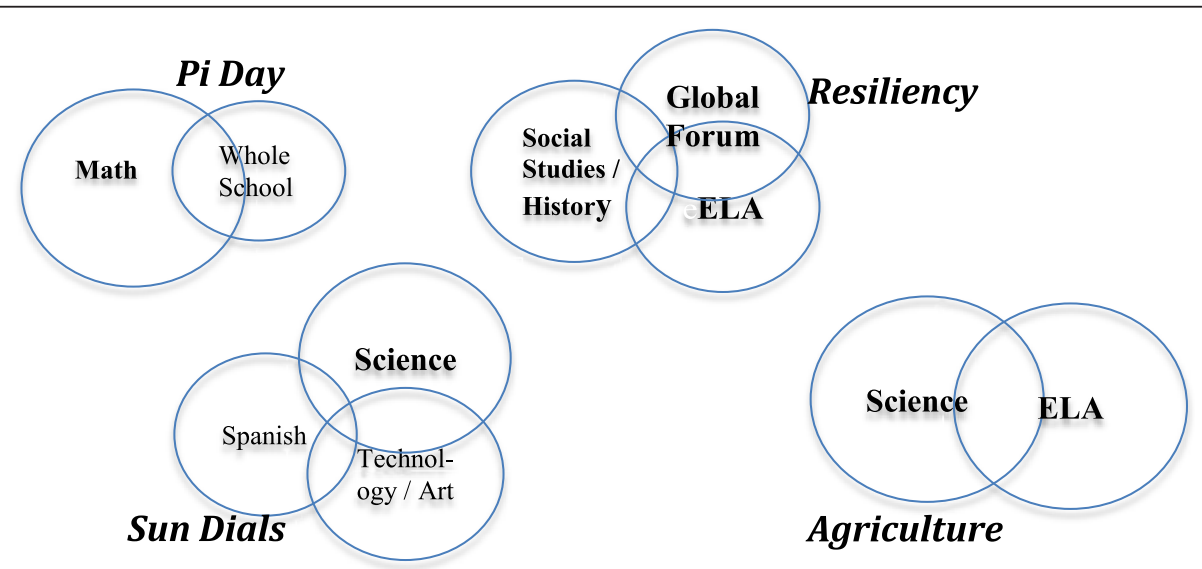

Fig. 3 Fewer projects, emergent interdisciplinary connections 


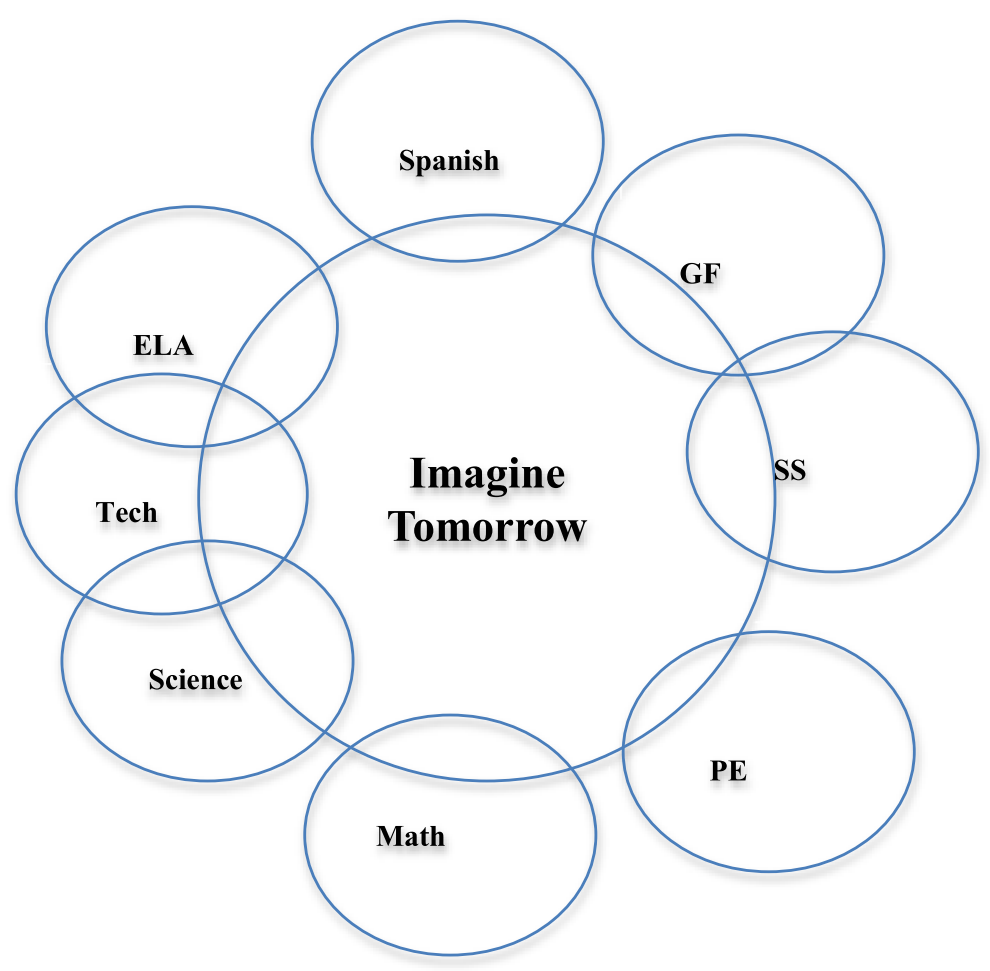

Fig. 4 Theme-based project

school's vision and the informed, collective actions of the teachers.

At the end of the year, three specific realizations were articulated by the teachers to improve the nature of future collective activity around the development of STEM-focused PBL learning experiences; first, broader interaction among all teachers, which was hindered by the A and B team split; second, a uniform approach toward PBL in which learning experiences built systematically and intentionally across classes, rather than merely being tied together by a common theme; and third, more time to collaborate prior to the opening of school and more than $1 \mathrm{~h}$ per week of teacher collaboration time.

The above collective activity of the teachers represents an enormous amount of risk-taking and the development and application of specific, nuanced understandings of curriculum and instruction in a STEM-based, multidisciplinary context. Benefitting from a variety of supports and addressing several challenges, the teachers were able to advance their shared vision of curriculum and instruction at RSA, and experiment with a variety of approaches in an iterative attempt at achieving this vision.

\section{Teachers' response to student needs: shaping the} curriculum and achieving buy-in

The teachers made intentional efforts to motivate and achieve buy-in from their students, and the curricular and instructional approach that emerged over the course of the year was reflected in these efforts. The teachers constructed a vision and then created the conditions and developed curriculum to move toward that vision. Student feedback throughout the year was a key source of information that the teachers used to make sense of this work. They responded to this feedback by carefully acclimating the students to the norms and processes of PBL, affording and pursuing student questions about STEM content, integrating disciplinary content knowledge, connecting the curriculum to STEM contexts and careers in flexible ways, and proactively eliciting and then responding to the needs of students.

The teachers made intentional efforts towards acclimating their students into STEM-based, multi-disciplinary curriculum. The PBL approach embraced by the entire school was a natural support for this effort. Common rubrics to evaluate projects, the development of norms for student collaboration during group work, and the requirement of student presentations upon project completion, often to outside audiences, were school-wide activities aimed at acclimating students to the vision and approaches at RSA. These efforts were rewarded, as the students interviewed at the end of the year spoke passionately and positively about their PBL experiences. For example, many students noted improvements in communication skills from the project experiences, with one 
student stating, "Now we've done so many projects it's not even really a big deal anymore just to get up in front of people and start talking." The idea of PBL being "business as usual" was commonly held by the students, and they seemed adaptive to this instructional change. Students stated that the projects "apply a lot more to the real world and college and workplace than just right-or-wrong answer worksheets." Another explained that the use of essential questions allowed students "to explore in the direction that we want to go instead of just having to do research on one topic to find the one right answer." This comment suggests that the curriculum afforded natural invitations for students to pose their own questions and engage in student-based inquiry related to content learning goals. Students recognized that "there's not as much structure in the way that you have to do things" and seemed to consider this a benefit to the learning experience.

Overall, the student interview data highlight differences between the instruction at RSA to those approaches encountered previously at other schools and the ways in which the students negotiated these new approaches to learning. Specifically, the students appreciated the content integration afforded by the projects, the connections to STEM contexts and their own interests, and the emphasis on group work and communication.

Students also appreciated the efforts of the teachers to work together in constructing multi-disciplinary projects, as well as the integrated approach eventually settled upon by the RSA teachers (Fig. 4). One student noted the difficulties encountered early in the year, when multiple projects were being assigned simultaneously:

Because I personally think it's kind of overwhelming, the amount of projects we get. Because we've got like one project for every class and then a giant project and then sometimes a mini-project in every other class.

However, most of the students interviewed felt the challenging nature of the curriculum was manageable, particularly when projects were connected across courses:

I think it's fun. Because you can focus on one project for each class. Like one whole project for each class. I don't think you have to say, "Oh, great. I finished this project but now I've got to finish another." So I think it's easier to do one project for just multiple classes.

While many of the students had initial difficulties with the PBL environment, they were able to adjust to and eventually embrace this instructional approach. This appeared to be a direct result of the adjustments made by the RSA teachers as well as the resiliency of the students:

So we're kind of like the people they are testing it on, and can kind of help modify it to what best suits us.

Because usually in all our projects, the teachers modify it.

\section{Limitations}

This study examined teacher activity in a variety of professional contexts, including PD and collaborative instructional planning sessions. We acknowledge that this study does not incorporate a detailed analysis of actual classroom interactions that occurred over the course of the year, nor does it fully investigate instructional impacts on student learning. The research also draws on one school in a very specific context-an inclusive STEM-focused school in the USA.

\section{Conclusions}

What is the role of the teacher during innovative school start-up? It is a complex mixture of learner, risk-taker, inquirer, curriculum designer, negotiator, collaborator, and teacher. In line with the findings by Winger (2000) and Darling-Hammond et al. (2002), the RSA teachers' collective sense-making activity related to instructional planning and curriculum supported the transition from a negotiated school vision into instructional reality. The administrative staff overseeing RSA provided both intellectual and practical space for teacher creativity, and the teachers also received key supports regarding school visioning and collaboration. The specific permission to take risks in this innovative environment proved central to the advancements made by the teachers. Freedom to try, analyze, and try again defined the ultimate trajectory of the curriculum and instruction at RSA, leading to new understandings reflected in changed instructional approaches.

Starting a new school in the context of a specific reform effort is complex. Because the teachers took seriously the task of attending to their students' needs, the context became more dynamic. Through coparticipating in this work, the teachers at RSA developed new understandings of PBL, STEM-focused curriculum, and their students. Essentially, they were participating in their own design experiment (Cobb et al. 2003), feeding back new understandings into the next iteration of the project-based curriculum they were developing, and learning about their students' needs in relation to this new type of curriculum. The three-phase trajectory of the instructional vision and implementation involving PBL (described above) is a direct result of the contexts, 
supports, and limitations that framed the teachers' collective activity. A major challenge to this development was that almost all the frameworks used to design and redesign curriculum and instruction were developed in action. The teachers were provided frameworks by school and district personnel but needed to collectively make sense of and adapt them for their own instructional purposes. While the sense-making processes that led to their eventual frameworks were extremely valuable, the emergent and dynamic nature of the frameworks also left the teachers somewhat vulnerable to shifts in context and the demands of external learning standards. The teachers had some, but limited, time to do curricular and instructional activity (plan, implement, reflect, change), and had a large degree of safety and permission to experiment with these processes. However, additional time to reflect on the supports that were provided related to PBL and STEM-based instruction would have been useful, as both of these approaches were initially unfamiliar to nearly all the teachers.

This suggests the intellectual supports that teachers require in this context are numerous and must be carefully identified and nurtured (Darling-Hammond et al. 2002). Specifically, our case study reveals the following considerations for teachers and administrators who engage in STEM school start-up:

- Teachers' collective sense-making of PBL and STEMbased instruction must be carefully developed, keeping in mind the context of the specific learning environments in which it will be enacted by teachers

- The capacity of teachers to develop understandings conducive to effective school start-up is great, particularly when key supports are present and when risk-taking is allowed and encouraged

- These emergent understandings must be continuously monitored against any existing school vision related to PBL and STEM-based instruction and should also be continuously monitored as the instructional contexts and realities shift over time

- Key supports include intellectual frameworks related to PBL and STEM-based instruction; sample curricular projects; abundant collaboration time dedicated to curricular visioning and development; access to student demographic, attitudinal, and achievement data; and the freedom to take pedagogical risks

- Intellectual supports require large amounts of time to synthesize and eventually enact, and more than a few months prior to school start-up are necessary to fully engage and prepare teachers for the collective task of visioning, collaborating, and planning the curriculum and instruction of a new school

- External demands and constraints, such as those imposed on teachers by external learning standards, must also be balanced by the needs of learners and the instructional capacity of teachers.

The contexts, conditions, and demands embedded in the above recommendations can play a key role in shaping the curricular and instructional trajectory of schools during the start-up phase. At RSA, the teachers learned to access their growing understandings of STEM-based, PBL instruction within the disciplinary demands imposed upon them by external, disciplinary learning standards and created various instructional approaches that addressed the perceived needs of their students.

The teachers' collective sense-making activity, viewed from a sociocultural perspective, generated understandings of curriculum and instruction that informed the dynamic vision of the school and led to changes in their approach to classroom practice. The teachers were also developing a vision of the school identity, constructed from emergent understandings of the externally provided goals for this STEM-focused school and from a better understanding of their student population. This was, in some ways, easier for them to do than curriculum building, as they were largely experienced teachers with empathy and commitment to students. While trying to conceptualize the initial school vision, created prior to any of the teachers' involvement with RSA, they were also simultaneously internalizing the key components of an inclusive, PBL-based, STEM-focused school as it was developing. The teacher collaboration and curricular projects were a product of the formal professional development, teacher collaboration meetings, and informal conversations that defined the teacher interactions and ultimately led to a more workable vision for the school. Student voice was also heard and used, which led to buy-in and motivation for engaging in the projects. The teachers were able to utilize the supports they were given and navigate the contexts and limitations to produce curriculum and instruction of their own creation that was consistent with the developing vision at RSA and that responded to the needs of the students. This collective activity defined the teachers' multiple roles in the start-up and development of this innovative school.

Our narrative case study illustrates the enormous creativity and capacity of teachers in the demanding setting of school start-up. Our study confirms the power of doing and risk-taking in the context of teacher development. The dialectical relationship between knowing and doing is continuously manifested during teacher collaboration (Borko 2004; Cochran-Smith and Lytle 2009). The teachers in this study developed important perspectives as they emerged themselves in school start-up activity. The realities of working together to enact learning experiences for students led to important teacher 
development opportunities of both an individual and collective nature. Teachers are capable of finding ways of defining, reacting to, or overcoming key influences that often mitigate the opening of a school, including lack of shared visioning, planning, and decision-making (Turbin 2009). With adequate time and intellectual support, teachers can engage in collective visioning and instructional implementation that not only support school start-up but also foster individual and collective advancements in their own development.

\section{Competing interests}

The authors declare that they have no competing interests.

\section{Authors' contributions}

DS and TN led the research team and participated in all aspects of the research as described in the paper, including data collection, data analysis, and research oversight. DS was the lead author of the paper, and TN made significant contributions to the writing of the paper. $\mathrm{KL}$ provided post-study analytic support and made significant contributions to the writing of the paper. All authors read and approved the final manuscript.

\section{Authors' information}

David Slavit is the Boeing Distinguished Professor of Mathematics Education and Mathematics at Washington State University Vancouver. Dr. Slavit's research focuses on teacher development as well as student learning processes, particularly in regard to algebraic thinking. He has recently focused on curriculum and instructional development at STEM-focused schools. He teaches courses in math methods, educational psychology, doctoral courses in math education, math content, and a cross-disciplinary honors course.

Tamara Holmlund Nelson is a Professor of Science Education at Washington State University Vancouver. Dr. Nelson's research interests focus on the transformation of science teacher knowledge and beliefs and how teachers translate their new understandings into practice. Her current research focuses on secondary science and mathematics teacher development and systemic change, including the role of leaders in the change process. Dr. Nelson teaches courses in science methods, instructional technology, and doctoral courses in science education.

Kristin Lesseig is an Assistant Professor of Mathematics Education at Washington State University Vancouver. Dr. Lesseig's research interests involve mathematical knowledge for teaching and professional development related to promoting mathematical reasoning (i.e., conjecturing, generalizing and justifying) in the middle and secondary mathematics classrooms. She teaches elementary and secondary mathematics content and methods courses as well as foundational courses in education and educational research.

Received: 15 November 2015 Accepted: 20 March 2016 Published online: 31 March 2016

\section{References}

Borko, H. (2004). Professional development and teacher learning: mapping the terrain. Educational Researcher, 33(8), 3-15.

Clandinin, D. J. (2013). Engaging in narrative inquiry. Walnut Creek: Left Coast Press.

Clandinin, D. J., \& Connelly, F. M. (2000). What do narrative inquirers do? In Narrative inquiry: experience and story in qualitative research (pp. 48-62). San Francisco: Jossey-Bass.

Cobb, P. (1994). Where is the mind? Constructivist and sociocultural perspectives on mathematical development. Educational Researcher, 23(7), 13-20.

Cobb, P., Confrey, J., Lehrer, R., \& Schauble, L. (2003). Design experiments in educational research. Educational Researcher, 32(1), 9-13.

Cochran-Smith, M., \& Lytle, S. L. (2009). Inquiry as stance: practitioner research for the next generation. New York: Teachers College Press.

Cole, M., \& Wertsch, J. V. (1996). Beyond the individual-social antinomy in discussions of Piaget and Vygotsky. Human Development, 39(5), 250-256.

Creswell, J. W. (2008). Narrative research designs. In Educational research: planning, conducting and evaluating quantitative and qualitative research (3rd ed., pp. 511-550). Upper Saddle River: Pearson Education, Inc.
Darling-Hammond, L., Ancess, J., \& Ort, S. W. (2002). Reinventing high school: outcomes of the Coalition Campus Schools Project. American Educational Research Journal, 39(3), 639-673.

Erdogan, N., \& Stuessy, C. L. (2015). Modeling successful STEM high schools in the United States: an ecology framework. International Journal of Education in Mathematics, Science, and Technology, 3(1), 77-92.

Fan S-CC, Ritz JM (2014). International views of STEM education. In M. J. de Vries (Ed.) Proceedings of the pupils attitude toward technology conference, Orlando, Fl. http://www.iteea.org/File.aspx?id=39511\&v=a2bd6f55

Giles, C., \& Hargreaves, A. (2006). The sustainability of innovative schools as learning organizations and professional learning communities during standardized reform. Educational Administration Quarterly, 42(1), 124-156.

Glaser, B. G., \& Strauss, A. L. (1967). The discovery of grounded theory. Chicago: Aldine.

Gorard, S., \& Taylor, C. (2001). The composition of specialist schools in England: track record and future prospect. School Leadership \& Management, 21(4), 365-381.

Hargreaves, D. (2003). Education epidemic: transforming secondary schools through innovation networks. London: Demos.

Herschbach, D. R. (2011). The STEM initiative: constraints and challenges. Journal of STEM Teacher Education, 48(1), 96-122.

Honey M, Pearson G, Schweingruber H (Eds) (2014). STEM integration in K-12 education: status, prospects, and an agenda for research. Washington, DC: National Academies Press

Jennings, J. (2012). Reflections on a half-century of school reform. Washington, D.C. Center on Education Policy.

Johnson, C. C. (2012). Implementation of STEM education policy: challenges, progress, and lessons learned. School Science and Mathematics, 112(1), 45-55.

Larmer, J., \& Mergendoller, J. R. (2010). Seven essentials for project-based learning. Educational Leadership, 68(1), 34-37.

Lave, J., \& Wenger, E. (1991). Situated learning: legitimate peripheral participation. New York: Cambridge University Press.

Lynch, S. J., Behrend, T. S., Peters-Burton, E., \& Means, B. M. (2012). Multiple instrumental case studies of inclusive STEM-focused high schools: opportunity structures for preparation and inspiration (OSPrI). Paper presented at the annual conference of the American Educational Research Association, Vancouver, BC.

Lynch, S. J., Behrend, T., Burton, E. P., \& Means, B. (2013). Inclusive STEM-focused high schools: STEM education policy and opportunity structures. Puerto Rico: Paper presented at the annual conference of the National Association for Research in Science Teaching.

Marginson, S., Tytler, R., Freeman, B., \& Roberts, K. (2013). STEM: Country comparisons: final report. Melbourne: Australian Council of Learned Academies.

Marshall, S. P. (2010). Re-imagining specialized STEM academies: igniting and nurturing decidedly different minds, by design. Roeper Review, 32(1), 48-60.

Miles, M. B., Huberman, A. M., \& Saldaña, J. (2014). Qualitative data analysis (3rd ed.). Thousand Oaks: Sage Publications.

Morrison, J., Roth McDuffie, A., \& French, B. (2015). Identifying key components of teaching and learning in a STEM school. School Science and Mathematics, 115(5), 244-255.

Nathan, B. R., \& Nilsen, L. (2009). Southwestern Pennsylvania STEM Network long range plan. Pennsylvania: Southwest Pennsylvania Regional STEM Network.

National Research Council. (2011). Successful K-12 STEM education: identifying effective approaches in science, technology, engineering, and mathematics. Washington, DC: The National Academies Press.

Pfeiffer, A. I., Overstreet, J. M., \& Park, A. (2013). The state of science and mathematics education in state-supported residential academies: a nationwide survey. Roeper Review, 32(1), 61-70.

Pitt, J. (2009). Blurring the boundaries - STEM education and education for sustainable development. Design and Technology Education, 14(1), 37-48.

Rhodes, V., Stevens, D., \& Hemmings, A. (2011). Creating positive culture in a new urban high school. The High School Journal, 94(3), 82-94.

Rosebery, A. S., \& Puttick, G. M. (1998). Teacher professional development as situated sense-making: a case study in science education. Science Education, 82(6), 649-677.

Science and Engineering Education Advisory Group (2012). Supporting Scotland's STEM education and culture. The Scottish Government

Spradley, J. P. (1980). Participant observation. New York: Holt, Rinehart \& Winston. Stake, R. E. (1995). The art of case study research. Thousand Oaks: SAGE Publications. 
Tan, A. L., \& Leong, W. F. (2014). Mapping curriculum innovation in STEM schools to assessment requirements: tensions and dilemmas. Theory Into Practice, 53(1), 11-17.

Taylor, S. J., \& Bogdan, R. (1984). Introduction to qualitative research methods: the search for meanings. New York: Wiley.

Turbin, D. (2009). Planning an innovative school. Educational Management, Administration, \& Leadership, 37(3), 404-421.

Vopat, M. C. (2011). Magnet schools, innate talent and social justice. Theory and Research in Education, 9(1), 59-72.

Vygotsky, L. S. (1978). Mind in society: the development of higher psychological processes. Cambridge: Harvard University Press.

Weick, K. E., Sutcliffe, K. M., \& Obstfeld, D. (2005). Organizing and the process of sensemaking. Organization Science, 16(4), 409-421.

Wells, G. (1999). Dialogic inquiry: towards a socio-cultural practice and theory of education. New York: Cambridge University Press.

Wilson, S. M., \& Berne, J. (1999). Teacher learning and the acquisition of professional knowledge: an examination of research on contemporary professional development. Review of Research in Education, 24, 173-209.

Wineburg, S., \& Grossman, P. (Eds.). (2000). Interdisciplinary curriculum: challenges to implementation. New York: Teachers College Press.

Winger, A. (2000). Stimulating the supply and building the capacity of new schools and school developers. Seattle: Center on Reinventing Public Education.

Yetkiner, Z. E., Hamza, A., \& Capraro, R. M. (2008). Research summary: project-based learning in middle grades mathematics. Westerville: National Middle School Association. Accessed 6 October 2015, http://www.ncmle.org/docs/ ProjectBased_Math.pdf.

\section{Submit your manuscript to a SpringerOpen ${ }^{\odot}$ journal and benefit from:}

- Convenient online submission

- Rigorous peer review

- Immediate publication on acceptance

- Open access: articles freely available online

- High visibility within the field

- Retaining the copyright to your article

Submit your next manuscript at $\gg$ springeropen.com 